\title{
Percepções parentais sobre implicações da pandemia para a criança Pré-escolar
}

\author{
Parental perceptions of pandemic implications for the Preschool child \\ Percepción de los padres sobre las implicaciones de la pandemia para los niños en edad Preescolar
}

\author{
Andréia Vedana Romanzini \\ ORCID: https://orcid.org/0000-0002-1134-0620 \\ Universidade Luterana do Brasil, Brasil \\ E-mail: psicoromanzini@gmail.com \\ Aline Groff Vivian \\ ORCID: https://orcid.org/0000-0003-2628-629X \\ Universidade Luterana do Brasil, Brasil \\ E-mail: aline.vivian@ulbra,br \\ Leticia Botton \\ ORCID: https://orcid.org/0000-0003-0286-3670 \\ Universidade Luterana do Brasil, Brasil \\ E-mail: leticia.botton@ulbra.br
}

\begin{abstract}
Resumo
Diante da pandemia de Covid-19 torna-se necessário conhecer as questões emocionais e comportamentais enfrentadas pelas crianças durante o período de distanciamento social. O presente estudo teve como objetivo identificar as necessidades psicológicas e emocionais de crianças pré-escolares, com idades entre 4 e 6 anos, de duas escolas privadas de um município do Vale do Caí/RS. Participaram 6 pais, com idades entre 30 e 43 anos, todos possuíam ensino médio completo e eram casados. Trata-se de um estudo qualitativo, com delineamento de estudos de casos múltiplos. As entrevistas foram realizadas através do Google.Meet, os dados foram gravados e transcritos, submetidos à análise de conteúdo qualitativa de Bardin e software QSR NVIVO. Os resultados foram organizados em categorias acerca da percepção de pais a respeito das necessidades psicológicas e emocionais infantis, bem como estratégias de enfrentamento desenvolvidas pelos pais das crianças e as experiências vivenciadas nesse contexto. Destacou-se a importância da instituição de ensino presencial para o desenvolvimento saudável dos pré-escolares, conforme o relato de seus pais. A aprendizagem e o contexto escolar repercutem na saúde mental infantil, sendo importante que família e escola trabalhem juntos para o melhor desenvolvimento da criança.
\end{abstract}

Palavras-chave: Distanciamento social; Covid-19; Pré-escolares; Aprendizagem.

\begin{abstract}
In view of the Covid-19 pandemic, it is necessary to know the emotional and behavioral issues faced by children during the period of social withdrawal. The present study aimed to identify the psychological and emotional needs of preschool children, aged 4 to 6 years, from two private schools in a city in Vale do Caí/RS. Six parents participated, aged between 30 and 43 years, all of them had completed high school and were married. This is a qualitative study, with multiple case study design. The interviews were conducted through Google.Meet, the data were recorded and transcribed, submitted to Bardin's qualitative content analysis and NVIVO QSR software. The results were organized into categories about the perception of parents regarding the children's psychological and emotional needs, as well as coping strategies developed by the children's parents and the experiences lived in this context. The importance of the face-to-face educational institution for the healthy development of preschoolers was highlighted, according to their parents' reports. Learning and the school context have an impact on children's mental health, and it is important that family and school work together for the best development of the child.
\end{abstract}

Keywords: Social distancing; Covid-19; Preschoolers; Learning.

\section{Resumen}

Ante la pandemia de Covid-19, se hace necesario conocer los problemas emocionales y de comportamiento a los que se enfrentan los niños durante el periodo de retraimiento social. El presente estudio tuvo como objetivo identificar las necesidades psicológicas y emocionales de los niños preescolares, con edades comprendidas entre los 4 y 6 años, de dos escuelas públicas de un municipio de Vale do Caí/RS. Participaron seis padres, con edades comprendidas entre los 30 y los 43 años, todos ellos con estudios superiores y casados. Se trata de un estudio cualitativo, con diseño de estudio de casos múltiples. Las entrevistas se realizaron a través de Google.Meet, los datos se grabaron y transcribieron, y se sometieron al análisis de contenido cualitativo de Bardin y al software QSR NVIVO. Los resultados se organizaron en categorías sobre la percepción de los padres de las necesidades psicológicas y 
emocionales de los niños, así como las estrategias de afrontamiento desarrolladas por los padres de los niños y las experiencias en este contexto. Se destacó la importancia de la institución de la educación en el aula para el desarrollo saludable de los niños en edad preescolar, según los informes de sus padres. El aprendizaje y el contexto escolar influyen en la salud mental de los niños, y es importante que la familia y la escuela trabajen juntos para el mejor desarrollo del niño.

Palabras clave: Distanciamiento social; Covid-19; Preescolares; Aprendizaje.

\section{Introdução}

Crianças de 0 até 6 anos de idade encontram-se na etapa de educação infantil, fase em que se desenvolvem através do brincar e de atividades de pré-leitura, pré-escrita e pré-matemática. Para que as crianças que ingressam no ensino fundamental sejam capazes de um desenvolvimento sócio emocional saudável é necessário que a etapa da pré-alfabetização ocorra de forma eficaz, incluindo atividades que envolvem a motricidade ampla e fina, responsável pela escrita; a autorregulação emocional e das funções executivas, que promovem a sustentação atencional, automonitoramento de motivação intrínseca, postergação de ganhos, linguagem oral desenvolvida conforme a consciência fonológica, o vocabulário e processamento de narrativas, conhecimento básico de letras e números com noções de quantificação, entre outras. O desenvolvimento no período pré-escolar ocorre de forma ativa e com interação dependente (Aunio et al., 2019).

Um estudo recente realizado por Koslinski e Barthole (2021) incluindo 671 crianças, com idades entre 04 e 05 anos, matriculadas em 21 escolas públicas e privadas do Rio de Janeiro, entrevistou professores, responsáveis e crianças. Os resultados da pesquisa sugeriram que as desigualdades na aprendizagem aumentam conforme as diferenças no nível socioeconômico, demonstrando as repercussões sociais também na pandemia.

O estudo de Wang et al. (2020) demonstrou que o confinamento de 220 milhões de crianças e adolescentes, incluindo estudantes de escolas primárias, secundárias e pré-escolas implicou em impactos psicológicos, além de sentimentos de frustração, tédio, medo de infecção, informações inadequadas, perda financeira da família e falta de espaço pessoal em casa. Conforme destaca Linhares e Enumo (2020), o isolamento no ambiente familiar pode gerar prejuízo nas referências externas do contexto ampliado, retratado por exemplo pela escola e ambiente de trabalho, o que exige maior atenção à organização interna, tanto no sentido de estruturação do ambiente doméstico, quanto do fortalecimento dos recursos pessoais e da rede familiar.

Um estudo de Imran et al. (2020), aponta que um dos fatores que mais afetam a saúde mental infantil, está relacionado à idade destas, pois as crianças nem sempre conseguem expressar seus sentimentos, e desta forma precisam lidar com as emoções oriundas de eventos adversos. Papalia e Feldman (2013), os pais e cuidadores experienciam muitas emoções frente às mudanças causadas pela pandemia, sejam elas relacionadas à saúde ou por questões ligadas à crise financeira. Desse modo, precisam lidar com preocupações e demandas, o que influencia diretamente no estado emocional de seus filhos.

O Núcleo de Ciências pela infância - NCPI, realizou um estudo, em que, aponta evidências neurocientíficas que comprovam que o cérebro das crianças de 0 a 6 anos está reagindo, neste contexto epidêmico, da mesma forma que reagiria a conflitos e desastres naturais (Manitto et al., 2020). Além do medo e do estresse, foi observada irritabilidade, maior apego aos pais, agitação, infantilização nas falas e comportamentos regressivos. Estudos sobre desastres naturais, como terremotos e furacões, demonstram maior vulnerabilidade nas crianças após eventos estressores, mostrando impactos na saúde física, mental, no âmbito educacional e de desempenho (Kousky, 2016).

Ao pesquisar sobre o desenvolvimento cognitivo, Vygotsky (1982) percebeu que este ocorre a partir da interação social do indivíduo com o meio em que está inserido. Conforme Vygotsky (1998) o desenvolvimento das funções psicológicas superiores surge na infância, assim como, a fala humana e o desenvolvimento cultural. Sprang e Silman (2013) sugerem que o estresse nas fases iniciais de desenvolvimento infantil pode causar permanentes, alterações, na capacidade do eixo hipotálamo- 
pituitária-adrenal (HPA) em reagir ao estresse na vida adulta, com sequelas ao longo prazo para a saúde mental como um todo. Em crianças submetidas à quarentena, a média dos escores de estresse pós-traumático foi quatro vezes maior a curto e médio prazo quando comparado às crianças no período pré epidêmico.

Em função do distanciamento social, as crianças estavam fora das salas de aula, o que é essencial ao desenvolvimento humano e aprendizagem. As crianças além das perdas no processo de aprendizagem estão privados da convivência com seus pares, espaço onde ocorrem as trocas de experiências, compartilhamento de decisões, negociação de conflitos, adiamento de gratificações, exercício de controle de impulsos, enfrentamento de desafios, espera da sua vez, entre outras habilidades. (Holmes et al., 2020).

O Ministério da Saúde preconiza que o desenvolvimento infantil é um processo singular de cada criança, representado através das mudanças contínuas nas habilidades cognitivas, motoras, linguísticas e psicossociais. Este processo acontece, ainda, no período pré-natal, seguido dos primeiros anos de vida deste sujeito. O desenvolvimento infantil, também, diz respeito às influências ambientais e emocionais da criança. Ainda segundo a Organização Mundial de Saúde (OMS), o conceito de saúde é o estado de completo bem-estar físico, mental e social e não somente ausência de doença, inclusive para crianças.

Bowlby (1988) afirmou que a forma como cada sujeito se envolverá em suas relações interpessoais, será influenciada pelas representações a respeito de si mesmo e do outro, assim como a interação entre estes, que originam-se a partir das experiências com a figura de apego e do tipo de apego desenvolvido. Tais estruturas influenciam a representação que a criança terá de si mesma, dos outros e do mundo, norteando, desta forma, as suas experiências e emoções ao longo da vida. Segundo Wainer et al. (2016), para que haja representações cognitivas favoráveis e adequadas é necessário que o meio proporcione condições sociais, principalmente, no que se refere à qualidade da relação afetiva com os cuidadores primários. Para Freud (1940 como citado em Schmidt, 2011), no que diz respeito aos efeitos traumáticos ocorridos no desenvolvimento humano, em especial nas fases em que a criança é mais vulnerável, a experiência provoca uma reação patológica incomum, pois provoca exigências excessivas com relação à personalidade, isto ocorre quando esta, é exposta a nível de excitação, maior que a sua capacidade de elaboração.

Diante do exposto, com vistas à promoção da saúde mental de pré-escolares no contexto de distanciamento social, frente à pandemia do Covid-19, este estudo tem como objetivo identificar a percepção dos pais frente às repercussões emocionais e comportamentais de seus filhos. Buscou-se averiguar, também, os impactos no desenvolvimento destes, com relação ao desenvolvimento da aprendizagem.

\section{Metodologia}

Essa pesquisa qualitativa trata-se de um estudo de casos coletivo, que buscou compreender as repercussões do distanciamento social, para crianças pré-escolares. O estudo de caso é um processo específico para uma investigação qualitativa na qual se busca descobrir o que há de mais essencial e característico na situação em estudo (Yin, 2000). Os casos são escolhidos porque se acredita que seu estudo permitirá melhor compreensão, ou mesmo melhor teorização, sobre um conjunto ainda maior de casos (Stake, 2000).

Participaram do presente estudo cinco mães e um pai, de crianças pré-escolares de duas instituições de ensino privadas, em um município do Vale do Caí/RS. O município possui 25 escolas municipais, 17 escolas estaduais e nove escolas privadas, dentre as privadas, duas são de educação infantil ao ensino médio, as demais, se dividem entre, educação infantil, ensino médio e ensino profissionalizante. O município está situado no Vale do Rio Caí, na encosta inferior noroeste, sendo o município mais antigo da região do Vale do Caí, recentemente incluído na região metropolitana de Porto Alegre/RS, ficando a 
$55 \mathrm{~km}$ de distância da mesma. Sua população, de acordo com o Instituto Brasileiro de Geografia e Estatística - IBGE, é de 59.415 habitantes (Ibge, 2010).

Foram incluídos pais de crianças que frequentavam a pré-escola, entre quatro e seis anos de idade, cujos filhos estudavam na rede privada. Para serem incluídos na pesquisa, foi necessário estarem em trabalho home office, ou terem sido desligados de seus empregos há pelo menos dois meses, ou ainda, os que não realizarem trabalhos fora de suas residências. Foram excluídos os pais e ou responsáveis que receberam algum tipo de apoio profissional com relação aos filhos neste período. Além de crianças que não tiveram apoio dos pais nas tarefas escolares durante o isolamento social vivenciado pela pandemia da COVID-19 ou que possuem algum transtorno do neurodesenvolvimento.

Foram realizadas entrevistas de forma on-line, através da plataforma Google Meet, durante o período de abril a setembro de 2021, no total foram entrevistadas cinco mães e um pai, contabilizando sete crianças da pré-escola. Em função das entrevistas serem no formato on-line, muitos pais não aceitaram participar, alegando a falta de tempo.

Foi utilizada uma ficha sociodemográfica para caracterização dos participantes e um roteiro de entrevista semiestruturada (com perguntas sobre o grau de instrução do respondente, estado civil, profissão, idade, o nome da escola em que a criança estava matriculada e idade da mesma). A fim, de obter maiores informações sobre os genitores.

Os participantes que preencheram os critérios de inclusão foram abordados por e-mail e encaminhados para uma sala virtual onde receberam explicação sobre o estudo, seu objetivo, além de informações relacionadas aos princípios éticos e, após o aceite, os indivíduos assinaram o Termo de Consentimento Livre Esclarecido (TCLE) através do google forms. Na sequência, ocorreu a aplicação da ficha de dados sociodemográficos e posteriormente, o roteiro de entrevista. Esta entrevista foi gravada em áudio e vídeo, através da plataforma Google.Meet com um tempo médio de duração estimado em 50 minutos cada.

Um estudo de Schmidt et al. (2020) embasado em revisão da literatura técnico-científica sobre entrevistas on-line, por meio de consultas a portais de pesquisa e bases de dados PubMed, SAGE, SciELO, Springer, Wiley e Google Scholar, permitiu analisar as potencialidades e os desafios da realização de entrevistas online no contexto da pandemia do COVID-19. Entre os pontos fortes, citados pelos autores, estão a maior abrangência geográfica, economia de recursos financeiros, maior segurança dos participantes e entrevistadores por conta da pandemia da COVID-19, possibilidade de investigar tópicos sensíveis, acesso a grupos socialmente marginalizados. No entanto, muitas pessoas podem ter limitações de acesso à Internet e a equipamentos para participar de uma coleta de dados on-line, o que costuma ocorrer sobretudo em contextos de vulnerabilidade socioeconômica. Pesquisas com populações específicas, que eventualmente possuam dificuldades para utilizar as TICs, tais como os idosos, também tendem a ser mais afetadas no atual cenário.

As entrevistas foram gravadas em vídeo digital e transcritas posteriormente. Os dados resultantes das entrevistas foram analisados por meio da análise de conteúdo de Bardin (2011) e as categorias foram construídas a partir da leitura destes. A análise foi realizada com o auxílio do software QSR NVivo versão 10 (NVivo, 2012). O objetivo foi investigar as percepções parentais sobre as implicações da pandemia para a criança pré-escolar.

Os resultados foram analisados em três etapas, conforme Bardin (2011) sendo a primeira delas, a pré-análise, onde o material coletado, neste caso, os depoimentos dos pais participantes, foram organizados, de modo que pudessem começar a responder ao objetivo geral da pesquisa, de forma a elucidar a interpretação final do estudo; Segunda etapa, exploração do material, o texto foi explorado de forma sistemática, em função das categorias apresentadas na primeira etapa; Terceira etapa, os dados coletados foram submetidos à análise, de forma que pudessem elucidar as informações obtidas, após, foram feitas as inferências e interpretações obtidas.

A pesquisa foi aprovada pelo Comitê de Ética e Pesquisa em Seres Humanos (CEP) Resolução $n^{\circ}$ 466, de dezembro de 2012, da Universidade Luterana do Brasil - ULBRA, sob o número 4.565.877 e Certificado de Apresentação e Apreciação Ética - CAAE sob o n ${ }^{\circ}$ 40720020.8.000.5349. Ficando assegurado aos participantes da pesquisa o anonimato e o direito da 
recusa na participação, livres de qualquer dano, exposição ou constrangimento. A pesquisa foi conduzida respeitando os aspectos éticos previstos na Resolução № 466/2012 da Comissão Nacional de Ética em Pesquisa (CONEP), que aborda as exigências éticas e científicas fundamentais dos estudos envolvendo seres humanos, referenciais da bioética, visando assegurar os direitos e deveres do participante. Os materiais produzidos pela pesquisa ficarão sob a responsabilidade da pesquisadora da instituição, armazenadas as gravações geradas pelas entrevistas online, em um pendrive, sendo o mesmo arquivado na sala 124 do PPGProSaúde durante o prazo de cinco anos e após será destruído.

A tabela abaixo apresenta os participantes, conforme idade e nível de escolaridade da criança, escola a que pertence, profissão, grau de parentesco e idade do respondente.

Tabela 1. Dados sociodemográficos dos participantes.

\begin{tabular}{|c|c|c|c|c|c|c|}
\hline Aluno & Escola & Idade & Série & Profissão do respondente & Respondente & Idade \\
\hline Eva & A & 6 & Pré & Empresário/Sup. Incomp. & Pai & 35 \\
\hline Malu & $\mathrm{B}$ & 4 & Pré & Professora/Sup. Incomp. & Mãe & 37 \\
\hline Lara & A & 4 & Pré & Enfermeira/Sup. Comp. & Mãe & 43 \\
\hline Aldo & A & 4 & Pré & Coorden. Pedagógica/Mestranda & Mãe & 37 \\
\hline Mara & $\mathrm{B}$ & 6 & Pré & Psicóloga/Sup. Comp. & Mãe & 39 \\
\hline Lucas & $\mathrm{B}$ & 6 & Pré & Psicóloga/Sup. Comp. & Mãe & 39 \\
\hline Paulo & $\mathrm{B}$ & 6 & Pré & Aux. Saúde Bucal/Técnico & Mãe & 30 \\
\hline
\end{tabular}

Fonte: Elaborado pelos autores (2021).

Os participantes deste estudo tinham entre 30 e 43 anos, com filhos entre 4 e 6 anos de idade. Em sua maioria mães, somente um pai respondente. Com relação à instituição de ensino, foram 50\% de cada uma das escolas. O nível de escolaridade variou de ensino médio completo a mestrado.

\section{Resultados e Discussão}

A partir das falas dos participantes entrevistados e com base na literatura foram propostas três categorias: Percepção de pais a respeito das necessidades psicológicas e emocionais infantis; estratégias de enfrentamento desenvolvidas pelos pais das crianças neste período; e experiências das crianças neste período que serão explanadas após a síntese de cada caso.

\subsection{Síntese dos Casos}

\section{Caso 01}

Carlos, 35 anos, pai, empresário do ramo de transportes, superior incompleto, separado, dois filhos, com oito e seis anos de idade. Na residência moram o pai, a madrasta, sendo a filha de oito anos estudante do terceiro ano do ensino fundamental I da escola A e, o filho de seis anos aluno do pré da escola A. Durante o período de distanciamento social, quando as aulas foram suspensas, o pai precisou levar os filhos consigo para o trabalho, adaptando uma sala dentro do prédio, para que ambos os filhos pudessem estudar e brincar durante o dia.

O pai entende que a responsabilidade no cuidado das crianças é dele, e que a madrasta cabe o papel de auxiliá-lo no banho e nas refeições, nas demais atividades ele que assume. As crianças ficam com a mãe a cada 15 dias, pois a guarda é do pai. O mesmo comenta que na residência dele as crianças não têm acesso às telas, ele as mantém com atividades práticas, jogos 
e brincadeiras, pois acredita serem muito pequenas para terem acesso às tecnologias, já na residência da mãe, cada um deles faz uso de um tablet.

\section{Caso 02}

Leda, 37 anos de idade, mãe, professora, casada, dois filhos. Na residência moram pai, mãe e os dois filhos, a menina, de 10 anos de idade, estudante do quinto ano do ensino fundamental I da escola B, e o irmão de quatro anos de idade, estudante do pré da escola B. A mãe sendo professora acabou precisando adaptar locais diferentes dentro de casa, para que as suas aulas não interferissem nas aulas das crianças, então, a organização foi cada um em uma peça da casa, a mãe ministrava as suas aulas da cozinha. Para facilitar o acesso da filha de 10 anos, os pais resolveram antecipar a permissão ao uso do celular, e ela ganhou um de presente. Por ser professora, precisar ministrar aulas e, ao mesmo tempo, mãe, precisando organizar a rotina dos dois filhos, se sentia extremamente esgotada, o pai seguiu trabalhando presencial, então ela precisou administrar a casa, os filhos e o trabalho home office sozinha. As aulas da pré-escola aconteciam uma vez por semana e eram gravadas, isso deixava o filho menor agitado, ele não conseguia entender porque não tinha aula online regularmente, e atrapalhava as aulas da irmã constantemente.

\section{Caso 03}

Rosa, 43 anos de idade, mãe, enfermeira, casada, duas filhas. Na residência moram pai, mãe e as duas filhas, uma de 12 anos de idade, estudante do sétimo ano do ensino fundamental II da escola A, e a irmã de quatro anos de idade estudante do pré da escola A. A mãe não conseguiu ficar em casa em nenhum momento durante o ano de 2020, pois trabalhava em dois locais, sendo que, em um deles é professora do curso técnico de enfermagem à noite, e no outro, é secretária de saúde de um município durante o dia. No ano anterior, em função de permanecerem trabalhando de forma presencial, optaram por deixar a filha menor em uma creche clandestina, na casa de uma conhecida, que acolhia outras cinco crianças, nestas mesmas condições, de pais que precisavam trabalhar e não tinham com quem deixar os filhos, a menina permaneceu neste local, até o retorno das aulas presenciais em 2021. As atividades escolares eram feitas à noite em família e durante os finais de semana. A filha mais velha de 12 anos, ficava em casa sozinha, contando com assistência de uma vizinha, caso necessário. Antes da pandemia, a família tinha uma ajudante que cuidava da filha mais velha à tarde e, pela manhã cuidava da mais nova, durante a pandemia ela se afastou, pois era grupo de risco. Em 2021, a mãe se afastou do trabalho, durante um período, permanecendo em casa com as filhas, porém, em função das aulas já terem sido retomadas, a rotina foi mais tranquila.

\section{Caso 04}

Vera, 37 anos de idade, mãe, coordenadora pedagógica, realizava mestrado em educação, casada, dois filhos. Na residência moram pai, mãe e os dois filhos, um de dez anos de idade, estudante do quarto ano do ensino fundamental I da escola A, e o irmão de quatro anos de idade, estudante do pré da escola A. Durante os meses de abril e maio de 2020 permaneceram em total distanciamento, os quatro em casa. A mãe relatou a dificuldade na adaptação a rotina de cuidar da casa, das crianças e trabalhar em home office, antes da pandemia ela tinha uma ajudante que ficava na casa com as crianças no turno inverso, devido a ser grupo de risco, ela precisou se afastar, resultando em um acúmulo de tarefas à mãe. Durante o período de home office, a mãe relatou as dificuldades vivenciadas com relação ao seu trabalho, pois como coordenadora pedagógica de escola em período de aulas remotas, era muito solicitada por pais e professores. $\mathrm{O}$ filho menor, não entendia o fato da mãe estar em casa, mas não ser presente e disponível a ele, então, frequentemente, ele interrompia as reuniões. Por outro lado, o filho mais velho se tornou bastante responsável durante esse período, realizando as tarefas da escola e auxiliando a mãe nas atividades da casa, a ponto, de mãe optar por dispensar a auxiliar, pois não sentia mais necessidade deste apoio. 


\section{Caso 05}

Rosangela, 39 anos de idade, psicóloga, casada, dois filhos. Na residência moram pai, mãe e um casal de filhos gêmeos, de cinco anos de idade, estudantes do pré da escola B. Por ser psicóloga escolar, a mãe manteve as atividades de atendimento às salas virtuais da escola em home office e os atendimentos do consultório passaram a ser on-line. O pai esteve em home office, por um período. Por morarem no mesmo pátio que os avós paternos, as crianças mantiveram contato com eles, que por vezes, tomavam conta dos netos, quando ambos os pais precisavam se ausentar. As atividades escolares eram enviadas pela escola através do Google Class, a mãe explica que fazia como "uma salinha de aula" com ambos ao mesmo tempo, por estarem no mesmo período escolar, porém o menino era mais resistente, por não se adaptar bem ao formato de estudar em casa, e apesar de a mãe ser psicóloga escolar, não possui a docência, portanto, conforme relato da mesma, não tinha o manejo adequado para a pré-alfabetização dos filhos.

\section{Caso 06}

Alessandra, 39 anos de idade, mãe, trader, casada, dois filhos. Na residência moram pai, mãe e os dois filhos, um de oito anos de idade, estudante do terceiro ano do ensino fundamental I da escola B, e o irmão de quatro anos, estudante do pré da escola B. A mãe relata que apesar dos avós maternos e paternos das crianças morarem na mesma cidade, no início da pandemia em março de 2020, eles chegaram a ficar 50 dias sem se verem pessoalmente, isso foi bastante complicado para as crianças que estavam acostumados a verem os avós, praticamente, todos os dias. A mãe trabalha com exportação, viaja muito, relata que este período de distanciamento social, está deixando a relação dela com os filhos mais próxima, pois ela consegue dar mais atenção a eles, apesar de seguir com trabalho home office, diariamente tinha conferências. O filho menor apres entava resistência em assistir às aulas on-line e praticar as atividades solicitadas, então, era necessário alguém ficar com ele em tempo integral durante as atividades escolares, este papel foi dividido entre mãe e pai, conforme a disponibilidade apresentada no momento.

Abaixo seguem as três categorias exploradas, através das entrevistas, com pais. Sendo estas: Percepção de pais a respeito das necessidades psicológicas e emocionais infantis; estratégias de enfrentamento desenvolvidas pelos pais das crianças neste período; e experiências das crianças neste período.

\subsection{Percepção de pais a respeito das necessidades psicológicas e emocionais infantis}

Esta categoria reflete a percepção dos pais, frente às necessidades psicológicas e emocionais apresentadas por seus filhos, durante o período de distanciamento social e de que forma a pandemia foi experimentada por eles.

Os pais evidenciaram o medo apresentado por seus filhos em contrair Covid-19 ou que algum membro da família o contraísse. Conforme expressões a seguir: “depois que eles viam meus pais, eles choravam pra eles ir embora: 'não, não vai embora, tu não vai voltar amanhã, fica mais'. Ficaram meio assustados” (Alessandra); "Referindo o tempo todo que tinha medo do coronavírus" (Rosa); "naquele primeiro mês, foi o mês que todo mundo ficou com muito medo né, muito medo" (Vera). As situações de perdas e incertezas causadas pela pandemia do COVID-19 tendem a provocar nas crianças sentimentos de raiva, medo da doença e ansiedade pela perda do vínculo com pessoas, seja por distanciamento, adoecimento, ou até mesmo, a morte (Panksepp, 1998). A separação pode tornar a criança insegura e ansiosa. Quando a criança está longe da figura de apego, ela sente-se incomodada e não responde aos estímulos sociais de outras pessoas. Durante este momento em que está afastada da figura de apego a criança sofre, a demonstração desse sentimento chega através do choro e do protesto (Bowlby, 1988). O medo, provocado pela pandemia, pode alterar os níveis de ansiedade e estresse em indivíduos saudáveis, bem como, intensificar sintomas em pessoas com condições psiquiátricas anteriores (Ornell et al., 2020). 
Research, Society and Development, v. 11, n. 1, e33011124900, 2022

(CC BY 4.0) | ISSN 2525-3409 | DOI: http://dx.doi.org/10.33448/rsd-v11i1.24900

Durante as entrevistas surgiram falas relacionadas às características emocionais e mudanças comportamentais observadas pelos pais, sendo estas: "eles ficaram mais sensíveis assim, de chorar mais, mais dependentes, tipo assim, se eu tava na lavanderia, eles vinham tipo assim, “mãe, mãe, onde tu tá?” Tinha que me ver o tempo inteiro na frente dos olhos, entende” (Rosangela); “Eu notei que eles começaram a roer unha, por exemplo” (Alessandra); "Essa insegurança tenha sido para eles talvez o maior problema" (Carlos); "o impacto maior que foi essa questão de ansiedade assim, deles estarem ansiosos, né” (Alessandra). Conforme Papalia e Feldman (2013), a autorregulação emocional inicia na segunda infância, quando as crianças aprendem habilidades de expressar e compreender os seus sentimentos, tendem a comportar-se de maneira mais adaptada diante das manifestações de suas emoções. Estas habilidades, expressam-se melhor com o desenvolvimento dos infantis, crianças entre os 4 e 5 anos de idade, já conseguem identificar tanto o seu estado emocional, quanto o de outras pessoas. A mudança imposta no estilo de vida em função do distanciamento social, pode fazer com que as pessoas passem a se sentir ansiosas e inseguras, sendo comum encontrar sentimentos de solidão, comunicação pobre e perturbações no humor. Quanto maior for o tempo de afastamento das atividades cotidianas, piores os impactos para a saúde mental infantil, especialmente os comportamentos de evitação, raiva e ansiedade (Usher et al., 2020).

Os participantes falaram sobre as consequências das aulas on-line observadas no comportamento de seus filhos e o impacto negativo para o desenvolvimento da aprendizagem, através das seguintes falas: "O que eles menos queriam era estudar em casa, então a gente ficou muito perdido” (Leda); “As trocas que eles fazem no dia-a-dia, é no brincar que eles estão aprendendo, não é no eu sentar com ele e mostrar as cores” (Vera); "eu senti assim que ele não queria muito fazer, ele era um pouco mais resistente pra fazer, né. Enfim, por não ser o ambiente, por não ser a profe, ele era mais 'ai agora não' (Rosângela); "Não tem ainda a coordenação motora, aquelas habilidades finas, enfim, assim. E eu não tenho a paciência que deveria ter” (Rosa); “o meu pequeno eu acho que ficou com uma dificuldade da pandemia que é na questão, até a professora dele conversou comigo, na questão de pegar o lápis, de escrever, ele tem dificuldade” (Alessandra). De acordo com Wallon (1986) a evolução da criança é permeada de contrastes, associações e assimilações em relação ao meio ao qual está inserida. Para o autor, tais reações, principalmente as reações sociais, desempenham a função de maturação necessária no sujeito e, deste modo, as atividades coletivas agregam perfeitamente à aprendizagem ao construir e desconstruir o conhecimento através da interação. Ou seja, a educação através do afeto constitui uma premissa básica dentro de qualquer proposta curricular com planejamento consciente e adequado. Além disso, Almeida et al. (2020), é importante que a rotina escolar seja realizada de forma tranquila, respeitando as orientações pedagógicas, sem exigências excessivas aos filhos.

Com relação à rotina estabelecida pelas famílias neste contexto pandêmico, foram trazidas as falas relativas às mudanças durante o período de distanciamento: "Eu gosto de manter uma certa rotina, dorme no mesmo horário, acorda no mesmo horário, dificilmente a gente muda a nossa rotina” (Carlos); "essa mudança toda de rotina, esse peso, né, esse sentimento de a gente não poder se organizar, sabe" (Alessandra); "Se a gente ainda tivesse antigamente uma rotina de não sair, acredito que não ia afetar tanto né” (Leda). Os pais são os responsáveis diretos frente às instituições, com a responsabilidade de responder às demandas infantis, desta forma, exigem produtividade excessiva e rotinas rigorosas aos seus filhos. Neste atual cenário, e na forma que a educação infantil vem sendo praticada, está mudando sua identidade, que deveria ser de integração social e afetiva para uma maior racionalidade, produtivista e controladora (Santos, 2020).

Na primeira categoria, em síntese, os pais destacaram o medo apresentado pelas crianças em contrair o vírus ou que algum parente próximo contraísse, também foi trazido por eles, as alterações no comportamento dos filhos, como, ansiedade, insegurança e dependência, aspectos relacionados às dificuldades com relação às atividades escolares, também foram evidenciados. A seguir, serão apresentados os recursos promotores da saúde utilizados pelas famílias durante o período de distanciamento social. 


\section{Estratégias de enfrentamento desenvolvidas pelos pais das crianças neste período}

Esta categoria diz respeito à forma que as famílias encontraram para minimizar os efeitos do distanciamento social, na saúde mental de seus filhos, para amenizar o impacto experimentado por elas.

Os pais relataram as maneiras de amenizar as repercussões do distanciamento dos amigos e da família na vida de seus filhos, através de atividades ao ar livre e contato com a natureza : "Daí à tardinha a gente, eu sempre procurava fazer alguma coisa com eles, como a gente tem pátio, né, a gente tem cavalo, eu tentava interagir" (Leda); "Eventualmente dava uma volta de bicicleta, mas muito pouco e meu pai tem uma chácara, né, no interior e a gente ia muito na chácara, caminhava lá e brincava com os guris, mais lá na chácara mesmo, no final de semana” (Vera); “A gente saía, ia pro mato assim, ia pra fora, sabe" (Rosângela); "Sábado e domingo a gente tentava ir pra algum mato com eles, meus pais tem um sítio e aí a gente ia pro mato e tentava fazer com que eles saíssem da tecnologia” (Alessandra). Fernandes e Marchi (2020) apontam a natureza como fonte saudável do brincar, pois torna a rotina mais divertida e relaxante, ao passo que, melhora as relações familiares, brincadeiras simples tem um efeito bastante considerável na saúde mental. Conforme Dussel (2020) passar mais tempo, interagindo com a natureza, foi um dos benefícios do distanciamento social. Tais benefícios podem ser evidenciados em níveis menores de estresse e o aumento da sensação de calma, o que proporciona maior atenção às coisas que se passam ao nosso redor, assim como, estímulos ao funcionamento do sistema imunológico (Fernandes \& Trevisan, 2018).

Nesta segunda categoria, os pais trouxeram como eventos promotores da saúde mental infantil, as atividades promovidas por eles ao ar livre, os passeios de bicicleta, visitas ao sítio, ou seja, o contato com a natureza, utilizando-se das telas o mínimo possível. A terceira categoria abordada tratará da experiência vivenciada pelas crianças, na percepção dos pais.

\section{Experiência das crianças neste período}

Esta categoria reflete as percepções dos pais quanto às experiências de seus filhos neste período. A forma como as famílias enfrentaram as dificuldades e se redescobriram.

Quase todos os pais trouxeram percepções das experiências deste período, conforme pode ser lido em suas falas, que os intensificou a convivência: “A convivência pra mim, por ser pai, com eles é muito natural, é muito fácil” (Carlos); "A gente reaprendeu a conviver todos juntos dentro de um espaço no qual a gente só dividia ele, principalmente, no final do dia alí, no noturno né. Então a gente voltou a fazer as refeições juntos” (Rosa); “A questão dos laços afetivos, eles se fortaleceram mais né." (Vera); "eu acho o maior tempo de tá junto mesmo, assim sabe. De acompanhar assim essa fase de desenvolvimento, pertinho” (Rosângela); “A gente ficou mais presente nesse sentido, principalmente porque não tá viajando, né, tão fora de casa assim" (Alessandra).

Conforme Linhares e Martins (2015), a parentalidade positiva promove o cuidado físico, o que garante a alimentação, a higiene adequada e o vestuário; o cuidado emocional, sendo as atitudes que promovem o apego seguro, a segurança como proteção e autonomia nas tomadas de suas decisões; e o cuidado social que estimula as relações interpessoais ampliadas. A parentalidade positiva é fundamental no desenvolvimento das crianças de 0 a 6 anos de idade. De acordo com Brasil (2017), as crianças, através de seus gestos e movimentos são capazes de conhecerem e reconhecerem as funções de seus corpos, identificam as suas potencialidades, desenvolvem consciência sobre o que é seguro e o que pode colocar em risco a sua integridade física, tais atividades proporcionadoras deste desenvolvimento se encontram próximas ao próprio cotidiano vivido. Quando as crianças são privadas do compartilhamento com seus pares, esta consciência é prejudicada, pois a troca realizada com adultos acaba não proporcionando as experiências necessárias.

Alguns pais trouxeram aspectos diferentes para a vivência de seus filhos neste período, em que o medo se intensificou e foi sentido pelos próprios adultos e repassados aos seus filhos "os medos que a gente passa né... o medo da perda, angústia” 
(Carlos); "primeiro a questão da saúde né, geral. E a questão do estresse" (Vera); "o distanciamento da família" (Rosângela).

Para Dubey et al. (2020), o período de isolamento social foi marcado por vários fatores estressores para as crianças, assim como, manejo do tédio e monotonia, desapontamento, falta do contato presencial com os colegas, amigos e professores, espaço compartilhado em casa, menos atividades físicas com menos gastos calóricos, além de maior demanda do gerenciamento e autorregulação de sentimentos surgidos delas mesmas e de seus pais, com perdas financeiras e laborais durante o lockdown.

Nesta categoria, os pais trouxeram aspectos como, a união familiar, a convivência e as trocas experimentadas dentro do núcleo familiar. As particularidades e aspectos comuns dos casos serão relatados a seguir.

\section{Semelhanças e diferenças entre os casos}

Foi possível observar que todos os pais entrevistados, trouxeram falas muito semelhantes com relação ao contexto da educação e as dificuldades com relação à execução das atividades pré-escolares por seus filhos, neste período. Pelo fato de as crianças pertencerem a uma faixa etária em que estão em fase de pré-alfabetização, preparando-se para uma fase de maior exigência, esta dificuldade de se manterem sentados e realizar as atividades propostas ficou mais evidenciada. Os diferentes contextos familiares, onde os pais não possuem experiência em docência, tem outros filhos, estavam de trabalho home office, sobrecarregados, tristes, inseguros, cada um destes contextos interfere no desenvolvimento da aprendizagem infantil adequada.

Outro ponto, comum em todas as entrevistas, foi o quanto o período de distanciamento social acabou sendo benéfico para a aproximação da família nuclear, momentos saudáveis passaram a constituir a rotina familiar, como, realizar as refeições em conjunto até a, reaproximação do grupo familiar com reconstrução dos vínculos. Algo que pode ser experimentado de muitas óticas não saudáveis e até trágicas se contarmos as vidas perdidas, também apresenta algo de positivo, algo de aprendizagem, o reencontro familiar.

Apesar dos diferentes contextos, a que cada família estava exposta, às diferenças nos núcleos e papéis de cada um, todas elas tinham em comum as estratégias de promoção na saúde mental das crianças, proporcionando momentos de descontração com atividades ao ar livre sempre que possível, passeios no campo que proporcionaram uma ligação com a natureza e os animais. Brincadeiras, jogos, conversas, divisão de tarefas, de forma geral, foram estratégias que as famílias optaram para interagir com as crianças.

\section{Considerações Finais}

Diante dos aspectos abordados no estudo foi possível evidenciar a predominante preocupação dos pais com relação ao desenvolvimento escolar de seus filhos. A instituição de ensino é reconhecida como um local a ser explorado presencialmente, tendo-se em vista que o ambiente doméstico, por mais adaptado que possa ser, não oferece os mesmos estímulos gerados na troca com os pares, elemento fundamental para um desenvolvimento cognitivo e emocional saudável nas crianças pré-escolares.

Foi possível observar como estratégia, dos pais, na promoção da saúde mental de seus filhos, as fugas oferecidas por estes, durante os finais de semana e feriados, proporcionando maior liberdade e atividades ao ar livre as crianças, sendo estas, expostas a ambientes saudáveis com possibilidades de exercícios, os quais auxiliam na produção da serotonina, hormônio responsável pela regulação do sono, melhora cognitiva, bom humor, bem estar, entre outras.

Este estudo apresentou limitações quanto à disponibilidade dos pais para a realização das entrevistas, devido à sobrecarga de tarefas acumuladas por eles neste período. No entanto, a amostra homogênea favoreceu o entendimento de que, as escolas privadas, não estavam preparadas para o ensino on-line, bem como, o fato de os participantes terem condições de 
Research, Society and Development, v. 11, n. 1, e33011124900, 2022

(CC BY 4.0) | ISSN 2525-3409 | DOI: http://dx.doi.org/10.33448/rsd-v11i1.24900

viabilizar os equipamentos necessários para as atividades acadêmicas, o que não retrata a realidade da maioria das crianças em idade escolar. Novos estudos incluindo pré-escolares de diferentes níveis socioeconômicos podem ampliar a compreensão do tema.

\section{Referências}

Almeida, J. R. D., Vianini, M. C. D. S., Silva, D. M. Meneghin, R. A., Souza, G. D. \& Resende, M. A. (2019). O enfermeiro frente às práticas integrativas e complementares em saúde na estratégia de saúde da família. Revista Eletrônica Acervo Saúde. 18, e77. https://doi.org/10.25248/reas.e77.2019

Aunio, P., Korhonen, J., Ragpot, L., Törmänen M., Mononen R. \& Henning, E. (2019). Multi-factorial approach to early numeracy--the effects of cognitive skills, language factors and kindergarten attendance on early numeracy performance of South African first graders. International Journal of Educational Research. 97, 65-76. https://doi.org/10.1016/j.ijer.2019.06.01

Bardin, L. (2011). Análise de conteúdo. Edições 70

Bowlby, J. (1988). A secure base: parent-child attachment and healthy human development. Basic Books. https://www.semanticscholar.org/paper/A-SecureBase\%3A-Parent-Child-Attachment-and-Healthy-Bowlby/545b983942722792c0e0c48b699aced98323d13e.

Brasil. (2017). Ministério da Educação. Base Nacional Comum Curricular. Brasília: Ministério da Educação. http://portal.mec.gov.br/conselho-nacional-deeducacao/base-nacional-comum-curricular-bncc.

Dubey, S., Biswas, P., Ghosh, R., Chatterjee, S., Dubey, M. J., Chatterjee, S., Lahiri, D. \& Lavie, C. J. (2020). Psychosocial impact of COVID-19. Diabetes \& Metabolic Syndrome: Clinical Research \& Reviews,14(5),779-788. https://doi.org/10.1016/j.dsx.2020.05.035

Dussel, I. (2020). La escuela en la pandemia. Reflexiones sobre lo escolar en tiempos deslocados. Práxis Educativa. 15, 1-16. https://doi.org/10.5212/PraxEduc.v.15.16482.090

Fernandes, N. \& Trevisan, G. D. P. (2018). Cidadania ativa na infância: roteiros metodológicos. In Alberto, F. \& Picornell, A. (org.). Experiancias mundiales de ciudadania de la infancia e adolescência. (pp. 212-139). Editora UFPB. http://repositorium.sdum.uminho.pt/handle/1822/64625.

Fernandes, N.\& Marchi, R. (2020). A participação das crianças nas pesquisas: nuances a partir da etnografia e na investigação participativa. Revista Brasileira de Educação. 25, e250024.. https://doi.org/10.1590/S1413-24782020250024

Holmes, E. A., O’Connor, R. C., Perry, V. H., Tracey, I., Wessely, S., Arseneault, L., Ballard, C., Christensen, H., Silver, R. C., Everall, I., Ford, T., John, A., Kabir, T., King, K., Madan, I., Michie, S., Przybylski, A. K., Shafran, R., Sweeney, A., Worthman, C. M., Yardley, L., ... Bullmore, E. (2020), Multidisciplinary research priorities for the COVID-19 pandemic: a call for action for mental health science. The Lancet Psychiatry, 7(6), 547-560. https://doi.org/10.1016/s2215-0366(20)30168-1

Imran, N., Zeshan, M. \& Pervaiz, Z. (2020). Mental health considerations for children \& adolescents in COVID-19 Pandemic. Pakistan Journal of Medical Sciences, 36(COVID19-S4), COVID19-S67-S. https://doi.org/10.12669/pjms.36.COVID19-S4.2759

Instituto Brasileiro de Geografia e Estatística (2010). Perfil dos municípios Brasileiros: Censo 2010. Ibge. https://censo2010.ibge.gov.br/

Koslinski, M.\& Barthole, T. (2021) O impacto da pandemia do Covid-19 no aprendizado e bem estar das crianças. Fundação Maria Cecilia Souto Vidigal. https://www.fmcsv.org.br/pt-BR/biblioteca/impacto-covid-criancas/\#.

Kousky, C. (2016). Impacts of natural disasters on children. Future of Children, 26(1), 73-92. https://doi.org/10.1353/foc.2016.0004

Linhares, M. B. M. \& Enumo, S. R. F. (2020). Reflexões baseadas na Psicologia sobre efeitos da pandemia COVID-19 no desenvolvimento infantil. Estudos de Psicologia (Campinas), 37, e200089. https://doi.org/10.1590/1982-0275202037e200089

Linhares, M. B. M. \& Martins, C. B. S. (2015). O processo da autorregulação no desenvolvimento de crianças. Estudos de Psicologia (Campinas), 32(2), 281293. https://doi.org/10.1590/0103-166X2015000200012

Manitto, A. M., Chiesa, A. M., Abuchaim, B., Kirschbaum, C., Santos, D. N. D., Mello, D. F. D., Louzada, F. M., Brentani, H. P., Macedo, L. D., Fracolli, L. A., Bernardo, L. R., Silva, R. D., Castro, M., Linhares, M. B. M., Campos, M. M., Souza, M. T. D, Menezes Filho, N. A., Vasconcellos, P. M. D., Lerner, R., ... Serebrinic, V. J. (2020). Repercussões da Pandemia de COVID-19 no Desenvolvimento Infantil (Tradução de Melissa Harkin). Núcleo Ciência Pela Infância. Fundação Maria Cecilia Souto Vidigal. https://ncpi.org.br/wp-content/uploads/2020/05/Working-Paper-Repercussoes-da-pandemia-no-desenvolvimentoinfantil-3.pdf.

NVivo (2012). Qualitative Data Analysis Software (Version 10). QSR International Pty Ltd. https://www.qsrinternational.com/nvivo-qualitative-data-analysissoftware/home

Ornell, F., Schuch, J. B., Sordi, A.O. \& Kessler, F. H. P. (2020). "Pandemic fear" and COVID-19: mental health burden and strategies. Revista Brasileira de Psiquiatria, 42(3), 232-235. https://doi.org/10.1590/1516-4446-2020-0008

Panksepp, J. (1998). Affective Neuroscience: The Foundations of Human and Animal Emotions Oxford. University Press. https://psycnet.apa.org/record/199902235-000.

Papalia, D. E. \& Feldman, R. D. (2013). Desenvolvimento humano. Artmed editora.

Santos, B. D. S. (2020). A cruel pedagogia do vírus. Almedina. https://www.abennacional.org.br/site/wp-content/uploads/2020/04/Livro_Boaventura.pdf 
Research, Society and Development, v. 11, n. 1, e33011124900, 2022

(CC BY 4.0) | ISSN 2525-3409 | DOI: http://dx.doi.org/10.33448/rsd-v11i1.24900

Schmidt, B., Palazzi, A. \& Piccinini, C. A. (2020). Entrevistas online: potencialidades e desafios para coleta de dados no contexto da pandemia de COVID-19. Revista Família, Ciclos de Vida e Saúde no Contexto Social, 8(4), 960-966. https://doi.org/10.18554/refacs.v8i4.4877

Schmidt, G. R. (2011). Sigmund Freud, da psicoprofilaxia à educação psicanaliticamente esclarecida: um percurso. Paidéia, 21(48), 119-127. https://doi.org/10.1590/S0103-863X2011000100014

Sprang, G. \& Silman, M. (2013). Postt raumati c stress disorder in parents and youth aft er health- related disasters. Disaster Medicine an Public Health Preparedness. 7(1),105-110. https://doi.org/10.1017/dmp.2013.22

Stake, R. E. Case studies. In Denzin, N. K., Lincoln, Y. S. (ed.). (2000). Handbook of qualitative research. (pp. 435-454). Sage.

Usher, K., Bhullar, N. \& Jackson D. (2020). Life in the pandemic: Social isolation and mental health. Journal of Clinical Nursing, 29 (15-16), $2756-2757$. https://doi.org/10.1111/jocn.15290

Vygotsky, L. S. (1982). Obras Escolhidas: problemas de psicologia geral. Gráficas Rogar.

Vygotsky, L. S. (1988). Linguagem, desenvolvimento e aprendizagem. Ìcone.

Wainer, R., Paim, K., Erdos, R. \& Androla, R. (Org.). (2016). Terapia cognitiva focada em esquemas: integração em psicoterapia. Artmed.

Wallon, H. (1986). As origens do pensamento na criança. Manole.

Wang, G., Zhang, Y., Zhao, J., Zhang, J. \& Jiang, F. 2020. Mitigate the effects of home confinement on children during the COVID-19 outbreak. The Lancet, 395(10228), 945-947. https://doi.org/10.1016/s0140-6736(20)30547-x 